\title{
Glucosylceramide synthase is an essential regulator of pathogenicity of Cryptococcus neoformans
}

\author{
Philipp C. Rittershaus, ${ }^{1}$ Talar B. Kechichian, ${ }^{1}$ Jeremy C. Allegood, ${ }^{2}$ Alfred H. Merrill Jr., ${ }^{2}$ \\ Mirko Hennig, ${ }^{3}$ Chiara Luberto, ${ }^{1}$ and Maurizio Del Poeta ${ }^{1,4}$
}

\begin{abstract}
${ }^{1}$ Departments of Biochemistry and Molecular Biology, Medical University of South Carolina, Charleston, South Carolina, USA. ${ }^{2}$ School of Biology, Georgia Institute of Technology, Atlanta, Georgia, USA. ${ }^{3}$ Department of Molecular Biology, Scripps Research Institute, La Jolla, California, USA. ${ }^{4}$ Department of Microbiology and Immunology, Medical University of South Carolina, Charleston, South Carolina, USA.
\end{abstract}

\begin{abstract}
The pathogenic fungus Cryptococcus neoformans infects humans upon inhalation and causes the most common fungal meningoencephalitis in immunocompromised subjects worldwide. In the host, C. neoformans is found both intracellularly and extracellularly, but how these two components contribute to the development of the disease is largely unknown. Here we show that the glycosphingolipid glucosylceramide (GlcCer), which is present in C. neoformans, was essential for fungal growth in host extracellular environments, such as in alveolar spaces and in the bloodstream, which are characterized by a neutral/alkaline $\mathrm{pH}$, but not in the host intracellular environment, such as in the phagolysosome of macrophages, which is characteristically acidic. Indeed, a C. neoformans mutant strain lacking GlcCer did not grow in vitro at a neutral/alkaline $\mathrm{pH}$, yet it had no growth defect at an acidic $\mathrm{pH}$. The mechanism by which GlcCer regulates alkali tolerance was by allowing the transition of $C$. neoformans through the cell cycle. This study establishes $C$. neoformans GlcCer as a key virulence factor of cryptococcal pathogenicity, with important implications for future development of new antifungal strategies.
\end{abstract}

\section{Introduction}

Cryptococcus neoformans is an environmental yeast distributed worldwide and is the most common cause of fungal meningoencephalitis in immunocompromised hosts (1). Infection is initiated upon inhalation of spores or desiccated yeast. In the lung, the fungus proliferates in the alveolar space, and in immunocompetent subjects the infection is normally contained in this organ. However, in immunocompromised subjects, dissemination of the yeast cells from the lung to the brain can occur intracellularly (within host cells) and extracellularly (in the bloodstream), leading to the development of a life-threatening disease (2-4). Since C. neoformans is a facultative intracellular pathogen, many studies have addressed how the fungus survives and grows within host cells (2, 5-9), but how fungal cells survive and proliferate extracellularly is not well understood.

One of the cell surface molecules of this fungus is glucosylceramide (GlcCer), an antigenic glycosphingolipid that elicits an antibody response in patients affected with cryptococcosis (10) and in mice (11). GlcCer is synthesized by uridine diphosphateglucose:ceramide (UDP-glucose:ceramide) glucosyltransferases encoded by GlcCer synthase (GCS) genes, which catalyze the first step in glycosphingolipid biosynthesis leading to the formation of the membrane lipid GlcCer. Very little is known about the role and function of GCS in fungal cells. The synthesis of GlcCer is absent in the yeast Saccharomyces cerevisiae, but it has been demonstrated in other fungi, such as Pichia pastoris; in fungi pathogenic to plants,

Nonstandard abbreviations used: GCS, GlcCer synthase; GlcCer, glucosylceramide; $\left[{ }^{3} \mathrm{H}\right]-\mathrm{DHS}$, tritiated dihydrosphingosine; HPTLC, high-performance TLC; NBD, 7-nitro-2-1,3-benzoxadiazol-4-yl; NOE, nuclear Overhauser effect; pYES2-CnGCS1, pYES2 vector expressing C. neoformans GCS1; pYES2-HuGCS1, pYES2 vector expressing human GCS1; SDW, sterile distilled water; YNB, yeast nitrogen base; YPD, yeast extract/peptone $/ 2 \%$ dextrose.

Conflict of interest: The authors have declared that no conflict of interest exists. Citation for this article: J. Clin. Invest. 116:1651-1659 (2006). doi:10.1172/JCI27890. such as Magnaporthe grisea (12); in fungi pathogenic to humans, such as C. neoformans (10), Candida albicans (12-14), Aspergillus fumigatus $(15,16)$, Histoplasma capsulatum (17), Paracoccidioides brasiliensis (18), and Sporotrix schenckii (19); and in other fungi (reviewed in refs. 20-22). The gene encoding for GCS (GCS1) has been isolated from P. pastoris, M. grisea, and C. albicans (12). The GCS1 gene has been deleted in the pathogenic fungus $C$. albicans, but its role in the pathogenicity of this fungus has yet to be elucidated.

Other studies have suggested a role for GlcCer in the regulation of fungal growth and pathogenesis. For instance, in C. neoformans GlcCer is mainly localized in the cell wall and mostly accumulates at the budding site of dividing cells. Interestingly, antibodies against C. neoformans GlcCer produced by patients affected with cryptococcosis inhibit budding and division of C. neoformans cells grown in vitro (10) as well as differentiation and germ-tube formation of Pseudallescheria boydii and C. albicans (23). Additionally, production of antibodies against fungal glycolipids has been demonstrated in patients with paracoccidioidomycosis (24), although in this disease the antibodies are mostly interacting with galactosylceramide instead of GlcCer. In other fungi, disruption of the GlcCer biosynthetic pathway altered spore germination, hyphal development, and fungal growth $(16,25)$. Monoclonal antibodies against fungal GlcCer have been produced (11), and, interestingly, treatment with anti-GlcCer antibody enhanced macrophage function against the fungus Fonsecaea pedrosoi (26). Together, these studies suggest an important role for GlcCer in fungal cell growth and differentiation and - because germ-tube formation and hyphal growth are provirulent factors - also suggest that GlcCer might be implicated in the regulation of fungal virulence. Thus we wondered whether GlcCer would have a role in the development and progression of cryptococcosis.

Here we have identified that GCS is a key regulator of pathogenicity of C. neoformans by ensuring cell cycle progression and 
A

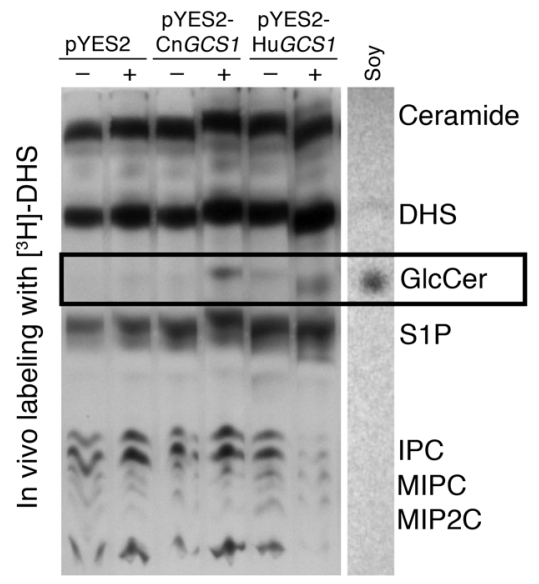

\section{B}

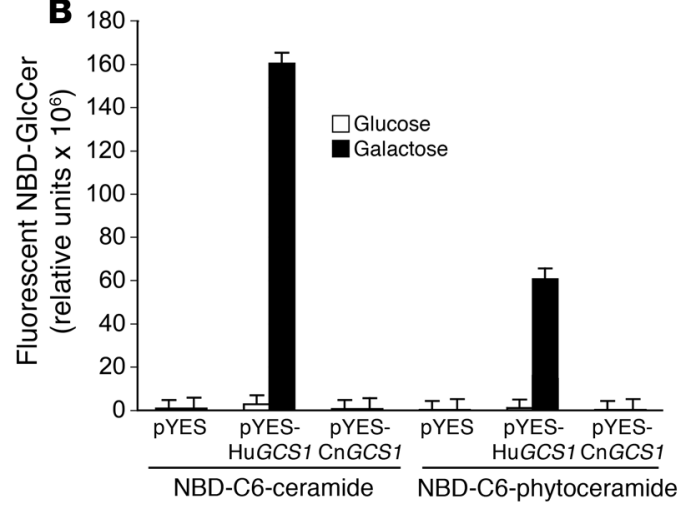

Figure 1

Expression of GCS1 genes in S. cerevisiae. (A) In vivo labeling in $S$. cerevisiae with $\left[{ }^{3} \mathrm{H}\right]-\mathrm{DHS}$. Expression of cryptococcal and human GCS1 produced GlcCer (boxed region) in galactose (+), but not in glucose (-). DHS, dihydrosphingosine; S1P, sphingosine-1-phosphate. Inositol phosphoryl ceramide (IPC), mannose-IPC (MIPC), and mannose-(inositol phosphoryl)2 ceramide (MIP2C) are complex sphingolipids. (B) In vitro assay in S. cerevisiae using NBD-C6-ceramides. Proteins extracted from yeast cells expressing pYES2-HuGCS1 and incubated with NBD-ceramides produced NBD-GIcCer under induction by galactose. NBD-GlcCer production was not observed in yeast cells expressing pYES2-CnGCS1 or pYES2 empty vector.

growth of fungal cells in environments characterized by neutral/ alkaline $\mathrm{pH}$ and physiological concentrations of $\mathrm{CO}_{2}$. Since these environments are characteristically found in the lung alveolar spaces, GCS regulates survival of C. neoformans upon inhalation through the respiratory tract, with important implications for the dissemination of fungal cells to the brain and the development of meningo-encephalitis.

\section{Results}

The C. neoformans GCS1 gene encodes for GCS activity. By sequence homology to the human GCS CDNA, a candidate C. neoformans GCS1 CDNA was identified. To investigate the potential activity of the C. neoformans GCS1 gene product as a GCS, the effect of GCS1 expression on sphingolipid metabolism was studied in S. cerevisiae, which totally lacks endogenous GCS activity. The human GCS gene was also expressed in a pYES vector as a positive control, and S. cerevisiae carrying the pYES empty vector was used as a negative control. Yeast cells were labeled in vivo with tritiated dihydro- sphingosine ([$\left.{ }^{3} \mathrm{H}\right]-\mathrm{DHS}$; Figure 1A), a precursor of ceramide/phytoceramide (the substrate of GCS) in mammalian and yeast cells. The results showed that, when induced by galactose, C. neoformans Gcs1 produced a radiolabeled sphingolipid that migrated similarly to a soy GlcCer standard; this sphingolipid was absent when repressed by glucose. As expected, expression of human GCS1 showed the formation of the putative GlcCer under conditions of induction but not repression (Figure 1A). Cells carrying the empty vector lacked this sphingolipid under conditions of induction and repression. These results suggest that C. neoformans Gcs1 is functional when expressed in S. cerevisiae and that it may use endogenous ceramides as substrates.

Mammalian GCS efficiently recognizes fluorescently labeled short-chain ceramide analogs as substrates in vitro and in vivo. To study the substrate specificity of the C. neoformans Gcs1, 7-nitro2-1,3-benzoxadiazol-4-yl-C6-ceramide (NBD-C6-ceramide) and NBD-C6-phytoceramide were tested as substrates in vitro, using cell protein extracts of S. cerevisiae expressing C. neoformans GCS1 or human GCS genes, under conditions of induction or repression. In contrast to what we observed for human GCS, C. neoformans Gcs1 did not recognize NBD-C6-ceramides as substrates (Figure 1B). The inability of C. neoformans Gcs1 to use short-chain fluorescent ceramide analogs was also confirmed by in vivo labeling using NBD-ceramides (data not shown). Together, these results show that C. neoformans Gcs1 does not share the same substrate specificity as human GCS.

C. neoformans Gcs1 produces GlcCer. To examine whether the C. neoformans GCS1 gene encodes for GCS, the C. neoformans GCS1 gene was deleted in the C. neoformans var. grubii strain (WT), creating the $\Delta g c s 1$ mutant, and was subsequently reconstituted, generating the $\Delta g c s 1+$ GCS1 strain (Supplemental Figure 1; supplemental material available online with this article; doi:10.1172/JCI27890DS1). To verify that the C. neoformans $\Delta g c s 1$ mutant lacks the putative GlcCer, in vivo labeling using [ $\left.{ }^{3} \mathrm{H}\right]$-DHS in WT, $\Delta g c s 1$, and $\Delta g c s 1+$ GCS1 strains was performed. As illustrated in Figure 2A, a radiolabeled compound that migrated onto a TLC similarly to the soy GlcCer standard was clearly lost in the $\Delta g c s 1$ strain, whereas it was completely restored in the reconstituted strain. Use of NBD-ceramides in C. neoformans for in vitro or in vivo labeling did not result in the formation of the corresponding identifiable sphingolipid in the tested strains (data not shown), in agreement with the finding that C. neoformans Gcs1 expressed in S. cerevisiae was unable to recognize NBD-ceramide analogs as substrates.

To confirm that the missing sphingolipid in the $\Delta g c s 1$ is GlcCer, we purified and concentrated the putative sphingolipid from C. neoformans strains, and the extracted lipids were analyzed by high-performance TLC (HPTLC), electrospray tandem mass spectrometry, and NMR. The analysis of the purified lipid extracts onto the HPTLC plate stained with orcinol clearly showed a band of a sugar-containing lipid migrating in tandem with the GlcCer standard from soy. This band was absent in the $\Delta g c s 1$ strain and reconstituted in the $\Delta g c s 1+G C S 1$ strain (Figure 2B).

The structure of the GlcCer was confirmed by syringe infusion of the glycosphingolipid into an API 3000 triple quadrupole mass spectrometer. Neutral loss scans of $m / z 180$ (loss of hexose headgroup), as well as precursor ion scans for the types of sphingoid bases commonly found in fungi, were performed. A major peak in C. neoformans WT was observed at $m / z 756.7$, which corresponded to a $[\mathrm{M}+\mathrm{H}]^{+}$charge for a monohexosylceramide with a lipid backbone composed of 37 carbons, 2 double bonds, and an additional 

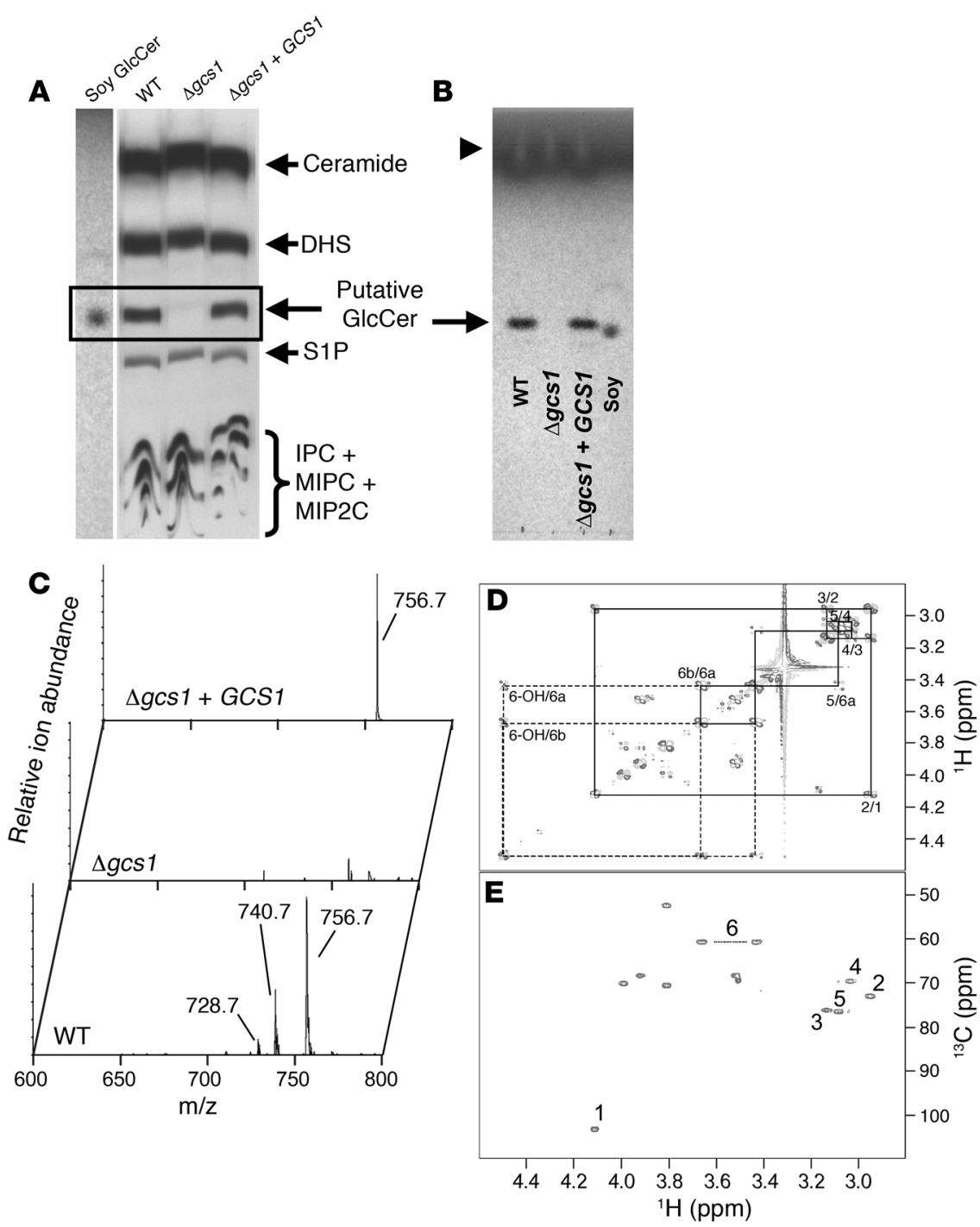

\section{Figure 2}

C. neoformans GCS1 gene encodes for GCS. (A) In vivo labeling of $C$. neoformans WT, $\Delta g c s 1$, and $\Delta g c s 1+$ GCS1 using [ $\left.{ }^{3} \mathrm{H}\right]$-DHS. The formation of GlcCer (boxed area) was examined by analysis of the extracted lipids onto a TLC. The soy GlcCer standard was visualized by iodine stain. (B) Analysis of purified GlcCer from the cultured strains using HPTLC. The lipids containing the sugar residues were visualized by staining with orcinol in $70 \%$ sulfuric acid, and the putative GlcCer is indicated. Plates were also stained with iodine to ensure equal lipid loading among the lanes (arrowhead). (C) Electrospray tandem mass spectrometric analysis of the glycosphingolipid analyzed on the HPTLC. The regions of the chromatogram indicated in $\mathbf{B}$ were extracted and analyzed by mass spectrometry as described in Methods. The indicated peaks are consistent with the $[\mathrm{M}+\mathrm{H}]^{+}$ions for monoexosylceramide with a methyl-sphingadienine backbone and a hydroxy-C18:1 fatty acid (the major species, $\mathrm{m} / \mathrm{z} 756.7$ ), a nonhydroxy-C18:0 fatty acid ( $\mathrm{m} / \mathrm{z} 740.7)$, and a hydroxy-C16:0 fatty acid ( $\mathrm{m} / \mathrm{z} 728.7)$. (D and E) ${ }^{1} \mathrm{H}-{ }^{1} \mathrm{H}$-double quantum filtered correlation spectroscopy (D) and ${ }^{1} \mathrm{H}-{ }^{13} \mathrm{C}$ heteronuclear single quantum correlation (E) NMR spectra of the monohexosylceramide WT extracted from the HPTLC. The solid connectivities in D among the 7 nonexchangeable hexose protons and their ${ }^{1} \mathrm{H}$ and ${ }^{13} \mathrm{C}$ chemical shift characteristics (E) show that glucose was attached to the ceramide backbone, defining this glycosphingolipid as GlcCer. Dashed connectivities in D identify the exchangeable $6-\mathrm{OH}$ in $100 \%$ dimethyl-sulfoxide- $\mathrm{d}_{6}$. hydroxyl (Figure 2C). Fragmentation of this ion yielded a product ion of $m / z$ 276.4, which identified the lipid backbone as having an 18-carbon sphingadienine base with one additional methyl group (for a total of 19 carbons) plus an amide-linked hydroxyC18:1 fatty acid. This is consistent with the backbone structure of a GlcCer that has been previously isolated from this organism (9-methyl-4,8-sphingadienine in amide linkage to 2-hydroxyoctadecanoic acid) (10). Precursor ion scans for $m / z 276.4$ also revealed lower-abundance species that probably reflect GlcCer with a nonhydroxy-C18:0 fatty acid (at $m / z 740.7$ ) and a hydroxy-C16:0 fatty acid (at $m / z 728.7$ ). Precursor scans in the $\Delta g c s 1$ mutant revealed minor peaks also present in the WT spectrum, whereas none of these GlcCers were detected (Figure 2C). Importantly, the reconstituted strain displayed a strong $m / z 756.7$ ion for the major GlcCer of the WT cells; interestingly, the minor C18:0 and hydroxy-C16:0 species were not detected.

Since no standards are available for these compounds, liquid chromatography mobility could not definitely identify the sugar head group. Thus we performed 2-dimensional NMR spectroscopy to uniquely define the structure of the hexose moiety of the purified sphingolipid (WT), as shown in Figure 2, D and E. The NMR characterization of the hexose commenced with the assignment of the glycoside protons in the ${ }^{1} \mathrm{H}-\mathrm{NMR}$ spectrum of the monohexosylceramide (Supplemental Table 1). The unambiguous identification of the $\mathrm{H}^{\prime}$ ' anomeric proton was straightforward due to its unique chemical shift $\left({ }^{1} \mathrm{H}, \delta 4.17 \mathrm{ppm} ;{ }^{13} \mathrm{C}, \delta 103.11 \mathrm{ppm}\right)$ and doublet multiplicity $\left({ }^{3} \mathrm{H}_{\mathrm{H} 1^{\prime}, \mathrm{H} 2^{\prime}}, 7.7 \mathrm{~Hz}\right)$. A combination of 2-dimensional ${ }^{1} \mathrm{H}-{ }^{1} \mathrm{H}$-double quantum filtered correlation spectroscopy and total correlated spectroscopy spectra clearly revealed the complete hexose proton spin system, which was supported by the ${ }^{13} \mathrm{C}$ heteronuclear single quantum correlation data (Figure 2, D and E). The stereochemistry of the hexose could be unambiguously determined from the first 4 vicinal ${ }^{3} J$-coupling constants. The large ${ }^{3} \mathrm{HH}^{-}$-coupling constants observed $(>7 \mathrm{~Hz})$ indicated antiperiplanar orientations of the vicinal hexapyranose $\mathrm{H} 1^{\prime} / \mathrm{H} 2^{\prime}, \mathrm{H} 2^{\prime} / \mathrm{H}^{\prime}$

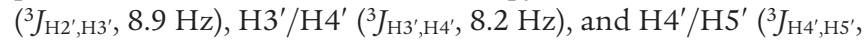
$9.1 \mathrm{~Hz}$ ) ring protons (Supplemental Table 1). The analysis of 1Dnuclear Overhauser effect (1D-NOE) difference experiments corroborated the previous $\beta$-glycopyranosyl assignment. NOEs were observed from $\mathrm{H}^{\prime}$ ' to $\mathrm{H}^{\prime}$ and $\mathrm{H}^{\prime}$; saturation at $\mathrm{H} 2^{\prime}$ produced a strong NOE at $\mathrm{H} 4^{\prime}$. Thus, based on our results and on previous NMR analysis of GlcCer species from other pathogenic fungi (27, 

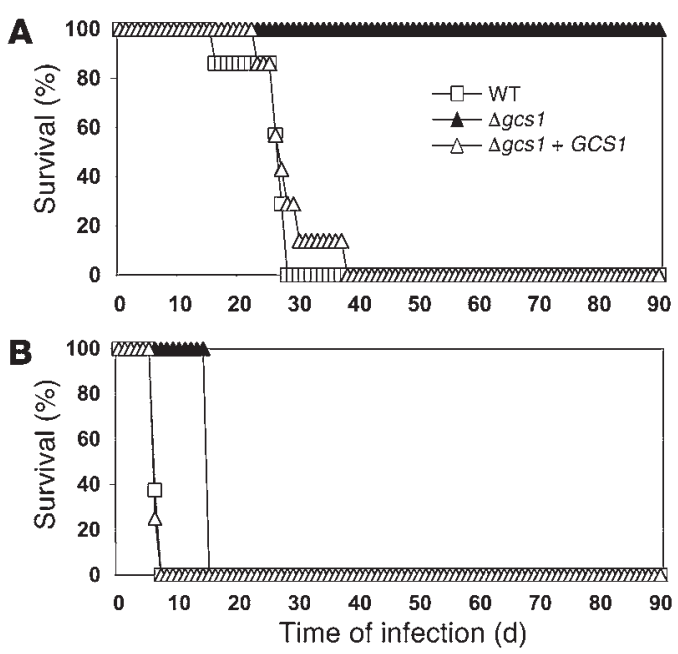

Figure 3

Survival studies of $C$. neoformans strains in a murine animal model. (A) CBA/J mice infected intranasally with $C$. neoformans cells. The average survival of mice infected with the C. neoformans WT and $\Delta g c s 1+$ GCS1 strains was $24.6 \pm 3.9$ days and $27.3 \pm 4.8$ days, respectively. All mice infected with $\Delta g c s 1$ mutant strain survived after 90 days of infection $(P<0.0001)$. (B) CBA/J mice infected intravenously with $C$. neoformans cells. The average survival of mice infected with the $C$. neoformans WT and $\Delta g c s 1+$ GCS1 strains was $6.3 \pm 0.51$ days and $6.2 \pm 0.46$ days, respectively, whereas the average survival of mice infected with $C$. neoformans $\Delta$ gcs 1 strain was 15 days $(P<0.01)$.

28), we conclude that glucose is attached to the ceramide backbone of the sphingolipid produced by the C. neoformans Gcs1 enzyme.

Role of Gcs 1 in the pathogenicity of C. neoformans. To determine the role of GCS1 in the pathogenicity of C. neoformans, we performed virulence studies using a murine animal model (CBA/J) of cryptococcosis. The average survival of mice infected intranasally with WT and $\Delta g c s 1+G C S 1$ strains was $24.6 \pm 3.9$ and $27.3 \pm 4.8$ days, respectively $(P<0.0001$; Figure $3 \mathrm{~A})$, whereas mice infected with C. neoformans $\Delta g c s 1$ were all alive after 90 days of observation. At the ninetieth day, even though the 11 mice infected with C. neoformans $\Delta g c s 1$ mutant showed no clinical signs of meningoencephalitis, they were sacrificed, and lungs and brains were removed and analyzed for CFUs and histology. Yeast cells were absent in 8 of 11 brains. The 3 yeast cell-positive brains showed approximately $6 \times 10^{5}, 500$, and 28,000 cells per organ. Among the 11 lungs, 6 lungs were used to determine fungal tissue burden, and an average of $5-10 \times 10^{3}$ yeast cells/lung were found, which corresponds to an approximately 100 -fold reduction of the initial inoculum. These results were confirmed by a study aiming to determine the lung fungal burden up to 70 days after infection with WT or $\Delta g c s 1$ strains (Supplemental Figure 2). These findings suggest that Gcs1 plays a key role in the pathogenicity of C. neoformans and growth of yeast cells in the lung.

To examine whether the lung environment plays a role in protecting the host against the dissemination of the $\Delta g c s 1$ strain, we challenged CBA/J mice intravenously with WT, $\Delta$ gcs 1 , and $\Delta g c s 1+$ GCS1 strains and monitored their survival. Mice infected with the WT and $\Delta g c s 1+G C S 1$ strains showed a similar average survival rate of $6.3 \pm 0.5$ days and $6.2 \pm 0.4$ days, respectively (Figure 3B). Mice infected with the $\Delta g c s 1$ mutant were apparently healthy until 13-15 days of infection, when they rapidly showed severe clinical signs of meningoencephalitis such as intense tremor, rigidity, lack of balance, and inability to coordinate movements. On the fifteenth day, mice were sacrificed because they were unable to reach food or water. Brains, lungs, kidneys, spleens, and livers were removed and assayed for tissue burden culture and histology. Analysis of CFUs of brains showed an average number of $8.4 \pm 0.06\left(\log _{10} \mathrm{CFU} \pm \mathrm{SD}\right)$ yeast cells, which was significantly higher $(P<0.01)$ than CFU in other organs ( $5.5 \pm 0.5$ in lung, $5.6 \pm 0.1$ in kidney, $5.3 \pm 0.2$ in spleen, and $5.6 \pm 0.1$ in liver). These results clearly suggest that when CBA/J mice are challenged intravenously, they cannot efficiently prohibit $\Delta g c s 1$ cells from disseminating throughout the body.

Inflammatory response against the C. neoformans $\Delta$ gcs1 strain. To examine the host inflammatory response against $C$. neoformans $\Delta g c s 1,5$ lungs and 5 brains from CBA/J mice challenged intranasally and 4 lungs and 4 brains of CBA/J mice challenged intravenously with C. neoformans $\Delta g c s 1$ were analyzed for histology. Figure 4, A-D, and Supplemental Figure 3, A and C, show representative fields from 4 different lungs recovered from mice infected intranasally. Supplemental Figure 3, E and G, show a representative field of 2 lungs and Supplemental Figure 3, F and H, show a representative field of 2 brains recovered from mice infected intravenously.

The lungs of mice challenged intranasally showed a strong granulomatous response consisting of the formation of extensive spheric nodules, in which $\Delta g c s 1$ cells were mainly trapped in the center with abundant necrotic tissue and numerous neutrophils (Figure 4). The necrotic tissue was surrounded by a ring of foamy macrophages and giant cells loaded with yeast cells and/or cellular debris or "ghosts" of yeast cells, which appeared to be degenerated (Figure 4C). The ring of macrophages was then surrounded by lymphocytes, fibroblasts, and fibrotic tissue (Figure 4A), in which a significant deposition of collagen was observed (Figure 4, $\mathrm{C}$ and D). These nodules ranged from 500 to $2,500 \mu \mathrm{m}$ in diameter and were confined in the lung, with no invasion into the mediastinal area. In other cases, smaller nodules were observed - such as those shown in Supplemental Figure 3, A and C - in which few C. neoformans cells were engulfed in macrophages surrounded by other macrophages containing "ghosts" of C. neoformans cells (Supplemental Figure 3B). Few lymphocytic interstitial infiltrations were localized in the proximity of the nodules (Supplemental Figure 3). Other portions of the lung appeared to be normal. These structures were present only in lungs infected with C. neoformans $\Delta g s c 1$, with different degrees of organization, whereas the nodules were not found in lungs of mice infected with the C. neoformans WT strain during the course of the infection (data not shown). All brains selected from mice infected intranasally with $\Delta g s c 1$ and analyzed by histology showed no sign of yeast cells.

Histology analysis was also performed on lungs, brains, and other organs of mice infected intravenously. In the lungs, $\Delta g c s 1$ cells were contained within small, spheric, nodule-like structures (Supplemental Figure 3, E and G) similar to those illustrated in Supplemental Figure 3, A and C. In the brain, C. neoformans cells were almost exclusively localized within brain abscesses of different size, which were not surrounded by any host inflammatory response (Supplemental Figure 3, F and H). Numerous abscesses containing $\Delta g c s 1$ cells were also found in the kidney (data not shown). In the liver, the $\Delta g c s 1$ cells were found in very small periportal lesions with no host cellular infiltrates, whereas in the spleen the $\Delta g c s 1$ strain was surrounded by a granulomatous response invading the white pulp and characterized by the presence of yeast cells surrounded by macrophages, lymphocytes, neutrophils, and 


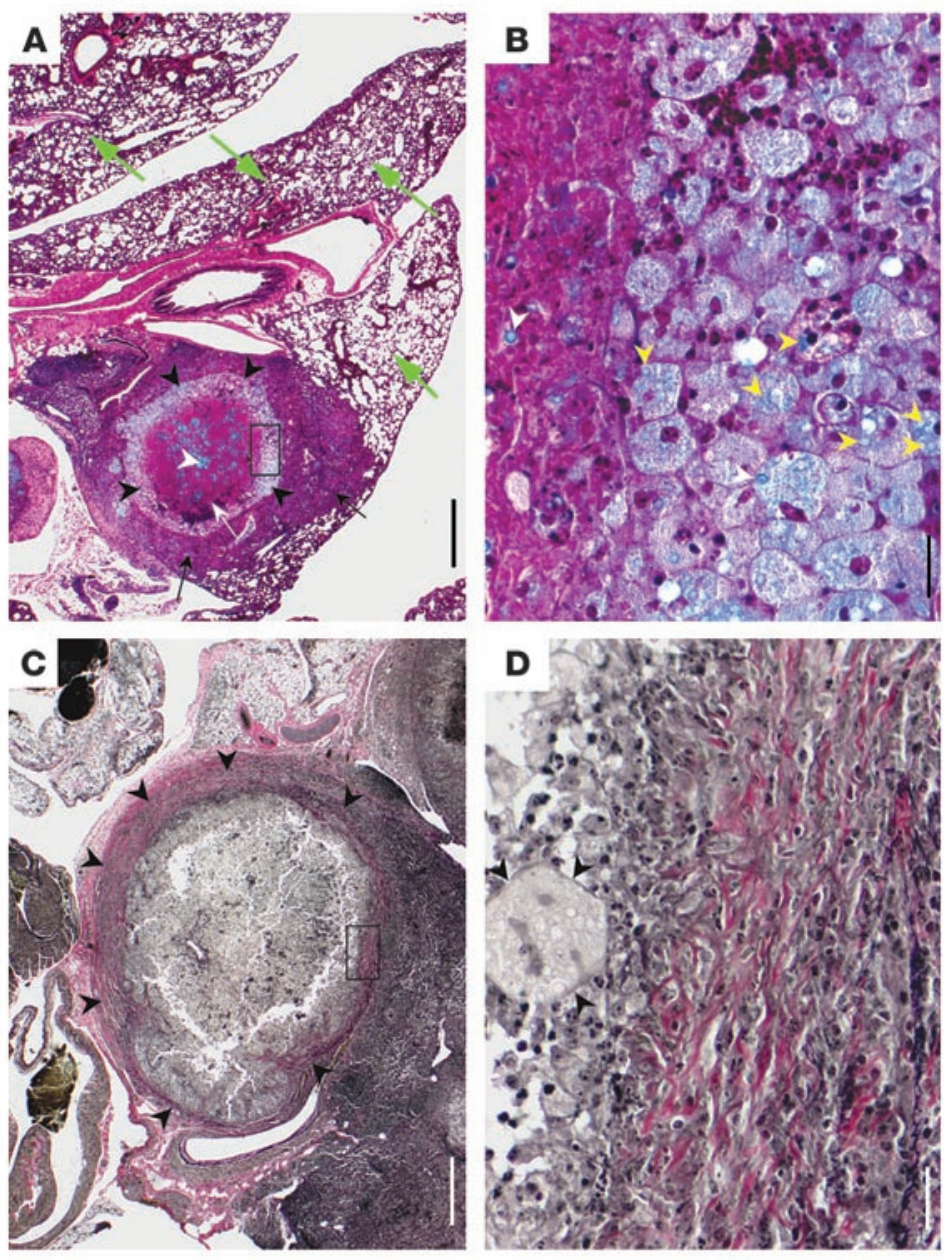

\section{Figure 4}

Histopathology of 2 different lungs obtained from CBA/J mice infected intranasally with the $C$. neoformans $\Delta g s c 1$ strain. (A and $\mathbf{B}$ ) Movat stain. (C and D) Verhoeff-van Gieson stain. Boxed areas in $\mathbf{A}$ and $\mathbf{C}$ are magnified in $\mathbf{B}$ and $\mathbf{D}$. In $\mathbf{A}$, white arrowhead indicates $C$. neoformans cells stained alcian blue, white arrow indicates necrotic tissue, black arrowheads indicate macrophages, black arrows indicate lymphocyte infiltration with fibroblasts and fibrotic tissue, and green arrows indicate normal lung tissue. In B, yeast cells (white arrowhead) were found within necrotic tissue. Also, many yeast cells appear as "ghosts" or degenerated cells (yellow arrowheads) within macrophages. In C, black arrowhead indicates collagen stained red in the peripheral of a nodule containing necrotic tissue, yeast cells, macrophages, and lymphocytes. In D, note the collagen deposition (red stain) between lymphocytes and fibrotic tissue. A giant cell in gray (black arrowheads) was loaded with $C$. neoformans in the internal side of the nodule, surrounded by granulocytes and lymphocytes. Scale bars: $500 \mu \mathrm{m}$ (A and $\mathbf{C}) ; 50 \mu \mathrm{m}$ (B and D).

shown in Figure 5A, the $\Delta g c s 1$ mutant was unable to grow at a neutral/alkaline $\mathrm{pH}$ in the presence of $5 \% \mathrm{CO}_{2}$ (Figure $5 \mathrm{~A}$ ), whereas growth was observed at an acidic $\mathrm{pH}$ (Figure 5B). This difference in growth was not observed in the presence of atmospheric $\mathrm{CO}_{2}$ concentration $(-0.04 \%)$ at $\mathrm{pH} 7.4$ or 4.0 (data not shown). Importantly, the growth defect at $5 \%$ $\mathrm{CO}_{2}$ and neutral $\mathrm{pH}$ was reversible because when yeast cells were switched to fresh acidic medium, cell growth was completely restored (data not shown), suggesting that growth of $\Delta g c s 1$ cells is arrested at alkaline $\mathrm{pH}$ and $5 \% \mathrm{CO}_{2}$.

To determine which phases of the C. neoformans cell cycle are affected by lack of GlcCer, we performed flow cytometry analysis of C. neoformans cells incubated for 24 hours and 36 hours at alkaline $\mathrm{pH}$ and $5 \% \mathrm{CO}_{2}$. We found that a significantly greater percentage of $\Delta g c s 1$ a few megakaryocytes (data not shown). These results suggest that when C. neoformans $\Delta g s c 1$ cells are introduced intranasally, the host organizes a strong granulomatous response, in which yeast cells are confined by macrophages, lymphocytes, fibroblasts, fibrotic tissue, and collagen deposition, with almost total containment of the infection within the lung tissue. In contrast, when yeast cells are introduced intravenously, C. neoformans $\Delta g s c 1$ cells do disseminate to the brain and other organs, eventually killing the animal.

Effect of Gcs1 on intracellular and extracellular growth of C. neoformans. In the host, C. neoformans proliferates intracellularly, within the acidic environment of the phagolysosome, and extracellularly, an environment characterized by alkaline/neutral $\mathrm{pH}$ and high $\mathrm{CO}_{2}$ concentration. Thus we investigated the effect of the loss of GlcCer on the growth of C. neoformans intracellularly and in in vitro acidic and alkaline environments. For intracellular growth, C. neoformans WT, $\Delta g c s 1$, and $\Delta g c s 1+G C S 1$ strains were incubated with J774.16 macrophage-like J774.16 cells, and the number of buds of internalized cells per phagocytic index was measured. As shown in Supplemental Figure 4, we found no differences in intracellular growth among the tested strains, suggesting that GlcCer has no effect on fungal growth once C. neoformans is internalized within macrophages.

In order to evaluate in vitro cell culture growth, we performed growth curves of C. neoformans WT, $\Delta g c s 1$, and $\Delta g c s 1+G C S 1$ strains incubated in $5 \% \mathrm{CO}_{2}$ at either a neutral/alkaline or an acidic $\mathrm{pH}$. As cells were locked in $\mathrm{S}$ and $\mathrm{G}_{2} / \mathrm{M}$ phases compared with the WT and $\Delta g c s 1+$ GCS1 cells at both 24 (Table 1) and 36 hours (data not shown), suggesting that GlcCer is important for exiting from the $\mathrm{S}$ and $\mathrm{G}_{2} / \mathrm{M}$ phases of the cell cycle.

\section{Discussion}

In the present study the role of C. neoformans GCS in the virulence of this pathogenic fungus was investigated. Our results show that C. neoformans GCS was an essential factor in determining the success of the fungal infection by regulating survival of C. neoformans during the initial colonization of the lung. In addition, we extracellular space by ensuring cell-cycle progression at neutral/ alkaline $\mathrm{pH}$ and physiologic $\mathrm{CO}_{2}$ concentration (Table 2).

The dramatic protection against pathogenicity imparted by loss of GCS underlines the importance of the extracellular compoinfects the host through inhalation, and upon its arrival in the alveoli it encounters 2 environments in which normally grows: the extracellular space, characterized by a neutral/alkaline $\mathrm{pH}$ and a physiologic $\mathrm{CO}_{2}$ concentration of approximately 5.0\% (compared to $0.04 \%$ present in the air, ref. 29); and the intracellular environment of the phagolysosome of alveolar macrophages, characterized by an acidic $\mathrm{pH}$. Our results suggest that GlcCer is critical for C. neoformans to grow in the extracellular (alkaline) but not in the found that GCS guaranteed survival of C. neoformans in the lung nent of fungal cells during C. neoformans infection. C. neoformans 

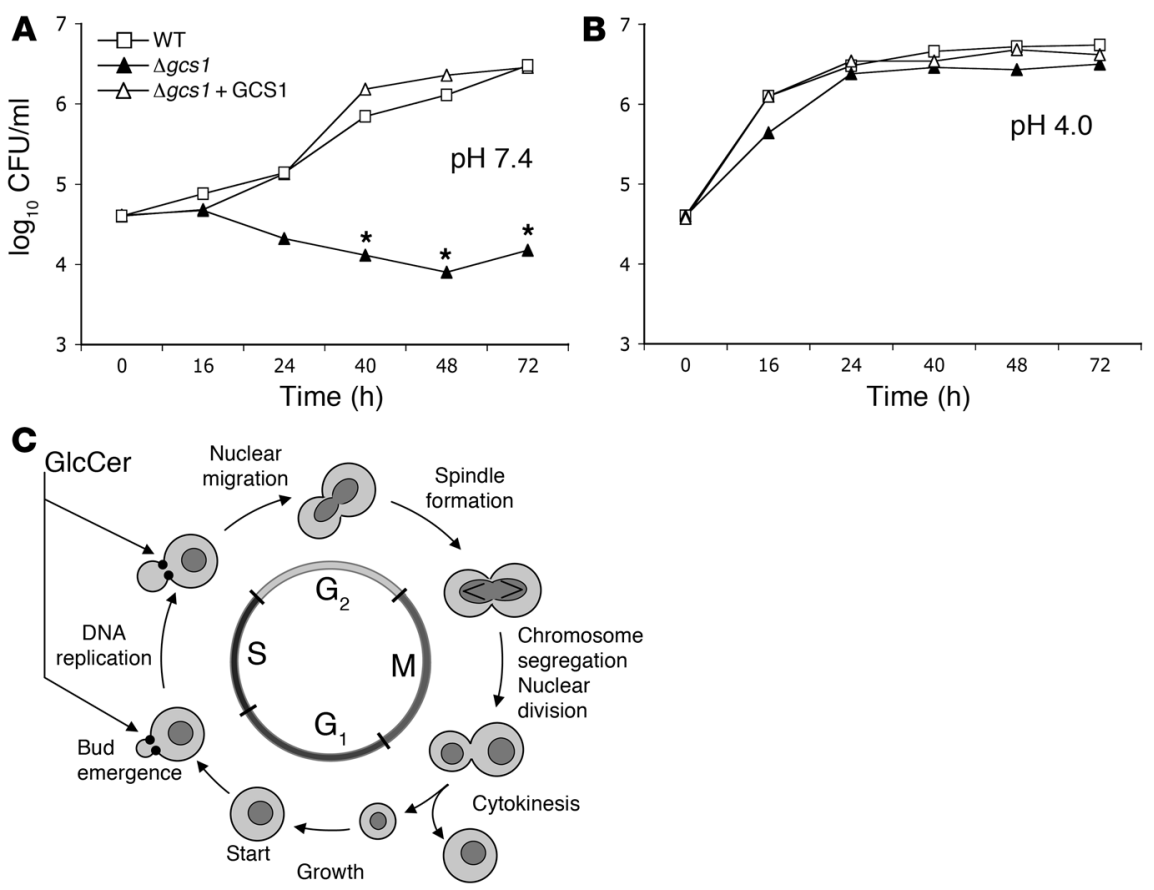

intracellular (acidic) environment of the lung. Since during the infection most C. neoformans cells are found in the host extracellular space (30), the overall effect of the loss of GlcCer on C. neoformans pathogenicity is significant. Indeed, when the $\Delta g c s 1$ strain was introduced intranasally, the overall growth of yeast cells in the alveoli was arrested (Supplemental Figure 2); even if the mutant grew intracellularly (Supplemental Figure 4), the host responded with the formation of well-organized granulomas (Figure 4 and Supplemental Figure 3), which efficiently contained $\Delta g c s 1$ cells in the lung. This allowed the host to survive the cryptococcal infection without any evident clinical sign of disease (Figure 3A).

When the $\Delta g c s 1$ strain was introduced intravenously, mice survived longer than those infected with the WT or reconstituted strains (Figure 3B). In the blood, $\Delta g c s 1$ also finds a hostile environment because the $\mathrm{pH}$ is approximately 7.4 and the $\mathrm{CO}_{2}$ concentration is approximately $5 \%$ (partial pressure of $\mathrm{CO}_{2}\left[\mathrm{pCO}_{2}\right], \sim 40$ $\mathrm{mmHg}$ ). Thus growth of $\Delta g c s 1$ cells in the bloodstream was arrested until yeast cells were either internalized by phagocytic cells or they left the bloodstream and invaded the organs, in which they formed abscesses such as those found in the brain (Supplemental Figure 3, F and H) and the kidney (data not shown). In both the intracellular environment and in abscesses, the $\mathrm{pH}$ was characteristically acidic, and growth of $\Delta g c s 1$ could resume. Indeed, it was interesting to note that in the brain upon intravenous challenge of $\Delta g c s 1$, yeast cells were almost exclusively contained within abscesses (Supplemental Figure 3, F and H), whereas in the WT strain, in addition to being present in abscesses, cells were also present in the surrounding tissue (data not shown). Thus we hypothesize that once the acidic abscess is formed, $\Delta$ gcs 1 cells promptly restore growth, and the consequent destruction of brain tissue will eventually manifest abruptly with clinical sign of meningoencephalitis. The animal infected intravenously with $\Delta g c s 1$ would eventually die, although it would take longer than mice infected with the control strains due to the transient growth arrest that yeast cells undergo in the bloodstream upon injection.

\section{Figure 5}

GlcCer is required for growth of $C$. neoformans cells in $5 \% \mathrm{CO}_{2}$ at $\mathrm{pH}$ 7.4. C. neoformans WT, $\Delta g c s 1$, and $\Delta g c s 1+$ GCS1 strains were grown in DMEM medium at $37^{\circ} \mathrm{C}$ in $5 \%$ $\mathrm{CO}_{2}$ at $\mathrm{pH} 7.4(\mathbf{A})$ and $\mathrm{pH} 4.0(\mathrm{~B}) .{ }^{*} P<0.001$, $\Delta g c s 1$ versus WT. (C) Succession of biological events characterizing a yeast cell cycle.

We believe the results from these studies identify GlcCer as a novel virulence factor for C. neoformans because loss of this glycosphingolipid does not affect other fungal characteristics, such as capsule production, melanin formation, or growth at ambient $\mathrm{CO}_{2}$ and $37^{\circ} \mathrm{C}$ (Supplemental Figure 5), known to be required to cause disease (1). Interestingly, a greater sensitivity of $\Delta g c s 1$ mutant to SDS was observed (Supplemental Figure 5), suggesting an alteration of cell wall integrity. This hypothesis is supported by previous observations of the corrleation of GlcCer density at the cell surface with the cell wall thickness of C. neoformans (10). However, the difference in cell growth of $\Delta g c s 1$ in the presence of SDS compared with control strains was not so dramatic to account for the significant loss of virulence of the mutant. Instead, the growth of $\Delta g c s 1$ mutant was arrested in environments characterized by alkaline $\mathrm{pH}$ and $5 \% \mathrm{CO}_{2}$.

In budding yeasts such as $C$. neoformans, the $S$ and $\mathrm{G}_{2}$ phases of the cell cycle are characterized by bud formation and maturation (Figure 5C). Interestingly, previous studies have shown that GlcCer is localized at the budding site of C. neoformans, and addition of human antibodies against C. neoformans GlcCer to in vitro C. neoformans culture inhibits cell budding and fungal cell growth (10). Our studies showed that loss of GlcCer significantly prolonged the $\mathrm{S}$ and the $\mathrm{G}_{2} / \mathrm{M}$ phases in alkaline environments, therefore suggesting a mechanism whereby GlcCer regulates fungal cell growth by allowing yeast cells to complete the cell cycle.

The role of GCS in alkaline tolerance is not restricted to C. neoformans, as recent findings showed that a Kluyveromyces lactis mutant defective in GlcCer cannot grow at pH 8.5 (31). On the other hand, the molecular mechanism by which GlcCer regulates alkaline tolerance at high but not low $\mathrm{CO}_{2}$ is not known. Studies have proposed that fungal cells sense different concentrations of $\mathrm{CO}_{2}$ and, in conditions in which $\mathrm{CO}_{2}$ is elevated (e.g., $5 \%$ ), fungi respond by upregulating virulence factors. For instance, $\mathrm{CO}_{2}$ stimulates capsule formation in C. neoformans (32) and the transformation

\section{Table 1}

Cell cycle analysis of $C$. neoformans strains

\begin{tabular}{lrcc} 
& \multicolumn{1}{c}{ WT } & $\Delta$ gcs1 & $\Delta$ gcs1 + GCS1 \\
$\mathrm{G}_{1}$ & $41.3 \pm 4.2$ & $20.8 \pm 3.2^{\mathrm{A}}$ & $40.4 \pm 1.5$ \\
$\mathrm{~S}$ & $1.5 \pm 1.5$ & $14.5 \pm 2.4^{\mathrm{A}}$ & $1.4 \pm 1.3$ \\
$\mathrm{G}_{2} / \mathrm{M}$ & $57.1 \pm 2.3$ & $64.6 \pm 1.6^{\mathrm{A}}$ & $58.1 \pm 1.2$
\end{tabular}

Analysis was performed after 24 hours of incubation in DMEM medium at $37^{\circ} \mathrm{C}$ in $5 \% \mathrm{CO}_{2}$ at $\mathrm{pH} 7.4$. ${ }^{\mathrm{A} P}<0.01, \Delta$ gcs 1 versus WT. 


\section{Table 2}

Pathobiological features of $C$. neoformans $\Delta g c s 1$ mutant strain

$\begin{array}{lc}\text { In vitro } & \\ \text { Capsule size } & \text { Similar to WT } \\ \text { Melanin production } & \text { Similar to WT } \\ \text { Growth at } 37^{\circ} \mathrm{C} \text {, ambient } \mathrm{CO}_{2} & \text { Similar to WT } \\ \text { Growth in } 0.05 \% \mathrm{SDS} & \text { Slightly decreased } \\ \text { Growth in } 1 \mathrm{M} \mathrm{NaCl} & \text { Similar to WT } \\ \text { Growth in } 1 \mathrm{mM} \mathrm{NO} & \text { Similar to WT } \\ \text { Growth in } 5 \mathrm{mM} \mathrm{H} \mathrm{O}_{2} & \text { Similar to WT } \\ \text { Growth at } 37^{\circ} \mathrm{C}, 5 \% \mathrm{CO}_{2}, \mathrm{pH} 4.0 & \text { Similar to WT } \\ \text { Growth at } 37^{\circ} \mathrm{C}, 5 \% \mathrm{CO}_{2}, \mathrm{pH} 7.4 & \text { Arrested } \\ \text { In vivo } & \\ \text { Phagocytic index } & \text { Similar to WT } \\ \text { Growth within macrophages } & \text { Similar to WT } \\ \text { Growth in the lung } & \text { Arrested (if infected i.n.) } \\ \text { Lung inflammation } & \text { Granuloma-like structure with collagen } \\ & \text { deposition (if infected i.n.) } \\ \text { Dissemination to the brain } & \text { Significantly decreased (if infected i.n.) } \\ \text { Mouse survival } & 100 \% \text { at } 90 \text { days (if infected i.n.) }\end{array}$

of yeast cells to filamentous forms in C. albicans through adenylyl cyclase (33). In other pathogenic fungi, such as Coccidioides immitis, $\mathrm{CO}_{2}$ promotes the formation of endosporulating spherules (34), which is a process required for virulence. These studies suggest the existence of a conserved signaling pathway that regulates fungal virulence through the sensing of $\mathrm{CO}_{2}$. C. neoformans senses $\mathrm{CO}_{2}$ through $2 \beta$-class carbonic anhydrases (Can1 and Can2), which have been recently identified $(35,36)$, but whether GlcCer regulates signaling events mediated by $\mathrm{CO}_{2}$-carbonic anhydrases at different $\mathrm{pHs}$ awaits further investigation.

In conclusion, these studies showed that GlcCer plays a key role in the pathogenicity of C. neoformans through a mechanism that ensures the transition through the cell cycle of yeast cells in alkaline environments with a physiological concentration of $\mathrm{CO}_{2}$. Since in cases of cryptococcosis extracellular organisms predominate, the function of GlcCer becomes clinically relevant. Interestingly, Gcs1 and GlcCer are found in a variety of pathogenic fungi, and because a significant biochemical difference between human and C. neoformans Gcs1 exists, compounds that would specifically inhibit the fungal enzyme might represent a novel class of antifungal agents against fungal infections $(16,25)$. Furthermore, since antibodies against the fungal GlcCer inhibit C. neoformans growth in vitro and do not interact with the human GlcCer (11), they may represent a new therapeutic approach to control infections by fungal microorganisms producing GlcCer.

\section{Methods}

Strains, plasmids, and growing conditions. The strains used in this study were the C. neoformans var. grubii serotype A strain H99 (WT), the $\Delta$ gcs 1 mutant derived from $\mathrm{H} 99$, and the $\Delta g c s 1+$ GCS1 reconstituted strain derived from $\Delta g c s 1$; as well as the S. cerevisiae strains JK9-3d $\alpha$ (MAT- $\alpha$, trp1, len2-3, his4, ura3, ade2, rme1) and JK9-3d $\alpha$ containing the pYES2 vector, the pYES2 vector expressing human GCS1 (pYES2-HuGCS1), and the pYES2 vector expressing C. neoformans GCS1 (pYES2-CnGCS1). Escherichia coli strains DH5- $\alpha$ (Invitrogen Corp.) and TOP10 (Invitrogen Corp.) were used in this study. Plasmids pBluescript SK (Stratagene) and pCR2.1-TOPO (Invitrogen Corp.) were used for cloning, and pYES2 (Invitrogen Corp.) was used for expression of GCS genes in S. cerevisiae. C. neoformans strains were routinely grown in yeast extract/peptone/ $2 \%$ dextrose-rich (YPD-rich) medium. S. cerevisiae strain JK9-3d $\alpha$ transformed with the pYES2, pYES2-HuGCS1, or pYES2-CnGCS1 vector was routinely grown in synthetic medium containing $6.7 \mathrm{~g} / \mathrm{l}$ yeast nitrogen base (YNB) without amino acids, $1.2 \mathrm{~g} / \mathrm{l}$ amino acid mixture lacking uracil, and $2 \%$ glucose or $1 \%$ glucose and $1 \%$ galactose for 16 hours at $30^{\circ} \mathrm{C}$ to induce either human or cryptococcal GCS1 gene expression. A full-length cDNA clone of the human GCS1 gene was cloned into pYES2 (Invitrogen Corp.) vector as described previously (37), generating the pYES2-HuGCS1 plasmid. Bacterial strains for plasmid amplification were routinely grown at $37^{\circ} \mathrm{C}$ in Luria-Bertani medium containing $75 \mathrm{mg} / \mathrm{l}$ of ampicillin (Sigma-Aldrich). DMEM (\#11995; BD Biosciences) buffered with HEPES at $\mathrm{pH} 7.4$ or $\mathrm{pH} 4.0$ was used for growing the C. neoformans strain at $37^{\circ} \mathrm{C}$ in presence of $5 \% \mathrm{CO}_{2}$.

Isolation and cloning of the C. neoformans GCS1 gene. The GCS1 gene from C. neoformans was identified by a BLAST search of the human GCS sequence (GenBank D50840) in the genome database of C. neoformans var. grubii serotype A strain H99 from Duke Center for Genome Technology (http://cneo. genetics.duke.edu/blast.html). One putative sequence, with an $\mathrm{E}$ value of $9 \mathrm{e}-51$ corresponding to $\mathrm{chr} 4 \mathrm{~B}$ piece 18 , was found. The GCS1 cDNA was then isolated by RT-PCR using the PRGCS-5' forward (5'-ATGAGCGATTCCGGCACATTGTCC- $\left.3^{\prime}\right)$ and reverse (5'-TCAATTTCTATCACCCAAACGAATTG-3') primers, and total RNA was extracted from C. neoformans strain H99. A 1,353-bp fragment was obtained, cloned into the pCR2.1TOPO vector generating plasmid pCR-CnGCS1, and sequenced. Amino acid alignment of C. neoformans Gcs1 with other Gcs1 proteins from different organisms revealed a homology (identity + similarity) of $47 \%, 16 \%$, 43\%, 46\%, 43\%, and 35\% to human, Arabidopsis thaliana, C. albicans, P. pastoris, M. grisea, and Aspergillus nidulans, respectively. The C. neoformans Gcs1 contains the motifs [D1, D2, D3 (R/QXXRW)] common to other GCSs required for GCS activity (38) and the characteristic N terminus hydrophobic transmembrane domain, which contains a signal-anchor sequence to the Golgi outer membrane (37). The C. neoformans GCS1 cDNA sequence was deposited in the GenBank database (AY956317). The GCS1 gene was deleted and reconstituted in the WT C. neoformans var. grubii strain, generating C. neoformans $\Delta g c s 1$ and $\Delta g c s 1+G C S 1$ strains (see Supplemental Methods).

In vitro growth studies. From overnight YPD broth cultures of $C$. neoformans WT, $\Delta g c s 1$, and $\Delta g c s 1+$ GCS1 strains, cells were washed twice in sterile distilled water (SDW), resuspended, and diluted into $40 \mathrm{ml}$ fresh YPD broth to a final density of $10^{4} \mathrm{cells} / \mathrm{ml}$ and incubated in a shaker incubator at $30^{\circ} \mathrm{C}$ or $37^{\circ} \mathrm{C}$. Aliquots were taken at the time points indicated in Supplemental Figure $5 \mathrm{~A}$, and serial dilutions were plated onto YPD plates for assessment of CFU. For in vitro growth studies on DMEM at $\mathrm{pH} 7.4$, 7.0 , or $4.0,10^{4}$ cells $/ \mathrm{ml}$ were incubated at $37^{\circ} \mathrm{C}$ in the presence of $5 \% \mathrm{CO}_{2}$, aliquots were taken at the time points indicated in Figure 5A, and serial dilutions were plated onto YPD plates for assessment of CFU. Capsule formation and melanin production were examined using media as previously described (1). For cell wall stability, cells were spotted in serial dilutions on YPD plates containing $0.05 \%$ SDS. For osmotic stress, cells were spotted in serial dilutions on YPD plates containing $1 \mathrm{M} \mathrm{NaCl}$. For oxidative or nitrosative stresses, cells were spotted in serial dilutions on YNB plates containing amino acids adjusted to $\mathrm{pH} 4.0$ and supplemented with $\mathrm{H}_{2} \mathrm{O}_{2}$ to a final concentration of $5 \mathrm{mM}$ or nitrite to a final concentration of $1 \mathrm{mM}$. After incubation at $30^{\circ} \mathrm{C}$ or $37^{\circ} \mathrm{C}$ for 72 hours, cell growth was examined and recorded by photography. Results show plates incubated at $37^{\circ} \mathrm{C}$.

For intracellular growth studies, J774.16 macrophage-like cells were used, and fungal growth of C. neoformans WT, $\Delta g c s 1$, and $\Delta g c s 1+G C S 1$ strains was determined as previously described (2, 5-9).

For cell-cycle studies, yeast cells were incubated in DMEM, $\mathrm{pH} 7.4$, at $37^{\circ} \mathrm{C}$ in the presence of $5 \% \mathrm{CO}_{2}$ for 24 and 36 hours. Cells were then washed twice 
with ice-cold water, sonicated, and fixed in $7 \mathrm{ml}$ of $95 \%$ ethanol for 16 hours. After fixing, the cells were pelleted, washed with $5 \mathrm{ml}$ of $50 \mathrm{mM}$ sodium citrate, resuspended in $1 \mathrm{ml}$ of $50 \mathrm{mM}$ sodium citrate containing $0.25 \mathrm{mg} / \mathrm{ml}$ RNase A, and incubated at $50^{\circ} \mathrm{C}$ for 1 hour. Next, proteinase $\mathrm{K}$ was added at a final concentration of $20 \mathrm{mg} / \mathrm{ml}$, and cells were kept at $50^{\circ} \mathrm{C}$ for an additional hour. Finally, $1 \mathrm{ml}$ of $50 \mathrm{mM}$ sodium citrate containing $50 \mu \mathrm{g} / \mathrm{ml}$ propidium iodine was added. Cells were kept for 24 hours in the dark at $4{ }^{\circ} \mathrm{C}$ and were analyzed using a BD fluorescence-activated cell analyzer. Data were modeled using the program ModFit LT (version 3.1; Verity Software).

In vitro activity assay of GCS. To express C. neoformans GCS1 gene in S. cerevisiae, the cDNA fragment was digested with EcoRI from pCR-CnGCS1 and subcloned into EcoRI-restricted pYES2 plasmid, generating pYES2CnGCS1. The S. cerevisiae JK9-3d $\alpha$ strain was chemically transformed with pYES2-CnGCS1 plasmid. Transformants were selected on YNB ura- agar plates containing $2 \%$ glucose, randomly chosen, purified, and stored. For gene induction, cell cultures were pelleted and washed twice with SDW. Cells were resuspended, inoculated into YNB ura- broth containing $1 \%$ galactose plus $1 \%$ glucose or $2 \%$ glucose, and incubated in a $30^{\circ} \mathrm{C}$ shaker for 16 hours. For in vitro GCS activity in C. neoformans strains, yeast cells were grown on YPD media in a shaker incubator for 24 hours at $30^{\circ} \mathrm{C}$, harvested by centrifugation, and washed with SDW, and pellets were stored at $-80^{\circ} \mathrm{C}$ if not used immediately. Once cells were collected, proteins were extracted as previously described (9) and quantitated by the method of Bradford (39). The in vitro GCS activity assay was performed by using the fluorescent ceramide analog NBD-C6-ceramide (Avanti Polar Lipids Inc.) as a substrate and monitoring the formation of NBD-C6-GlcCer as described previously (37), with some modifications. Briefly, $200 \mu \mathrm{g}$ of yeast proteins were incubated for 30 minutes at $30^{\circ} \mathrm{C}$ in $50 \mathrm{mM}$ bis-Tris- $\mathrm{HCl}$ buffer (pH 6.5) containing $12.5 \mathrm{mM} \mathrm{KCl,} 250 \mu \mathrm{M}$ EDTA, $50 \mu \mathrm{M}$ phosphatidylcholine, $500 \mu \mathrm{M}$ UDP-glucose, $5 \mathrm{mM}$ Triton X-100, and $20 \mu \mathrm{M}$ NBD-C6-ceramide in a final reaction volume of $100 \mu$. The reaction was terminated by the addition of $0.3 \mathrm{ml} \mathrm{CHCl}_{3} / \mathrm{MeOH}$ (1:1 ratio). The samples were mixed, and the phases were separated by centrifugation at $2,000 \mathrm{~g}$ for 5 minutes. The lower phase was dried down using the SPD 2010 Speedvac (Thermo Electron Corp.). The chloroform-soluble product was analyzed by analytical TLC on silica gel 60 plates (EM Science) using the solvent system chloroform/methanol/water (65:25:4). Purified GlcCer from soy (Avanti Polar Lipids Inc.) was also loaded onto the TLC plate and used as a standard (40). NBD-GlcCer was identified as a fluorescent band migrating in tandem with soy GlcCer and quantitated by direct fluorescence using a phosphorimager Molecular Dynamics Inc. 840 STORM unit and by ImageQuant analysis (GE Healthcare).

In vivo activity assay of GCS. Approximately 5 hours before cell collection, yeast cells were counted, and $5 \times 10^{7}$ cells were resuspended in the same growing media and incubated with $2 \mu \mathrm{M} / \mathrm{ml} \mathrm{NBD-C6-ceramide.} \mathrm{Similar} \mathrm{experi-}$ ments were performed using NBD-C6-phytoceramide, NBD-C12-ceramide, and NBD-C12-phytoceramide. Yeast cells were incubated for 5 hours, shaken at $30^{\circ} \mathrm{C}$. Cells were harvested by centrifugation for 10 minutes at $2,000 \mathrm{~g}$ and washed with SDW, and the total lipid was extracted using the method of Mandala et al. (41) followed by base hydrolysis. The extracted lipids were loaded onto a TLC using the solvent system chloroform/methanol/water (65:25:4 ratio). Formation of NBD-GlcCer was analyzed as described above.

For in vivo labeling using $\left[{ }^{3} \mathrm{H}\right]$-DHS, approximately 2 hours prior to cell collection, $5 \times 10^{7}$ yeast cells $/ \mathrm{ml}$ were incubated with $2 \mu \mathrm{Ci} / \mathrm{ml}$ of $\left[{ }^{3} \mathrm{H}\right]$-DHS for 2 hours at $30^{\circ} \mathrm{C}$ in the appropriate growing media in a shaker incubator. The cells were harvested by centrifugation (10 minutes at $2,500 \mathrm{~g}$ ), washed with SDW, and stored at $-80^{\circ} \mathrm{C}$ if not used immediately. Lipids were extracted as described by Mandala et al. (41) and after base hydrolysis were loaded onto a TLC plate and analyzed using a phosphoimager and quantitation of radioactive GlcCer performed by ImageQuant analysis. As a control, $10 \mu \mathrm{l}$ of $20 \mathrm{mM}$ soy GlcCer (Avanti Polar Lipids Inc.) was loaded onto a TLC plate and visualized using iodine stain.

Mass spectrometry analysis. Purified GlcCer was obtained as described in Supplemental Methods and used for mass spectrometry (MS) analysis. The MS and MS/MS scans of GlcCer were conducted using an API 3000 triple quadrupole mass spectrometer with electrospray ionization as described previously by Merrill et al. (42). The analyses used syringe infusion and included neutral loss scans (with $\mathrm{m} / z 180$ for loss of the hexose headgroup) and precursor ion scans for the characteristic product ion $m / z 276.4$.

$N M R$ analysis. NMR experiments were recorded in $500 \mu \mathrm{l}$ dimethyl-sulfoxide- $\mathrm{d}_{6}$ (Cambridge Isotope Laboratories Inc.) using $160 \mu \mathrm{g}$ putative monohexosylceramide obtained from HPTLC purification; subsequently, the sample was dissolved in dimethyl-sulfoxide- $\mathrm{d}_{6}$ and deuterium oxide $(98: 2, \mathrm{vol} / \mathrm{vol})$. NMR spectra were recorded on a Varian Inova $600 \mathrm{MHz}$ spectrometer equipped with an actively shielded $z$-gradient triple-resonance $\left({ }^{1} \mathrm{H},{ }^{13} \mathrm{C},{ }^{31} \mathrm{P}\right)$ probe at $25^{\circ} \mathrm{C}$. All spectra were processed and analyzed using FELIX 2000 Insights II version 2000 (MSI) and NMRPipe version 2.3 (43) program packages. ${ }^{1} \mathrm{H}$ chemical shifts were internally referenced to 3-(trimethylsilyl)-1-propane sulfonic acid. ${ }^{13} \mathrm{C}$ chemical shifts were referenced against the center line of the dimethyl-sulfoxide septet $(\delta=39.52$ $\mathrm{ppm}$ ). The decoupling in the presence of scalar interactions-2 (DISPI-2) mixing time was $62.6 \mathrm{~ms}$ (44). NOE difference experiments were measured with saturation delays of 6 seconds (45).

Virulence studies and histology analysis in a murine mouse model of cryptococcosis. Four- to 6-week-old CBA/J (NCI/Frederick Laboratories) mice were used. Mice were anesthetized with an intraperitoneal injection of $60 \mu \mathrm{l}$ xylazine/ ketamine mixture containing $95 \mathrm{mg}$ ketamine and $5 \mathrm{mg}$ xylazine per kilogram of body weight. C. neoformans WT, $\Delta g c s 1$, and $\Delta g c s 1+G C S 1$ strains were prepared by growing cells for 24 hours at $30^{\circ} \mathrm{C}$ in YPD medium. The cells were pelleted, washed twice, and resuspended in PBS, pH 7.4, at a concentration of $2.5 \times 10^{7}$ cells $/ \mathrm{ml}$. Ten CBA $/ \mathrm{J}$ mice were infected with $5 \times 10^{5}$ cells of WT, $\Delta g c s 1$, or $\Delta g c s 1+$ GCS1 strains in a volume of $20 \mu$ through nasal inhalation. Eight CBA/J mice were infected with $10^{6}$ cells of WT, $\Delta$ gcs 1 , or $\Delta g c s 1+G C S 1$ strains in a volume of $100 \mu l$ through tail vein injection. The mice were fed ad libitum and followed with twice-daily inspections. Mice that appeared moribund or in pain or with clinical signs of meningoencephalitis were sacrificed using $\mathrm{CO}_{2}$ inhalation followed by cervical dislocation. All animal procedures were approved by the Medical University of South Carolina Institutional Animal Care and Use Committee and followed the guidelines of the American Veterinary Medical Association. Histology analysis was performed as described in Supplemental Methods.

Statistics. Survival data from the mouse experiments were analyzed by Kluskal-Wallis test. For other statistical analysis, a 2-tailed Student's $t$ test was used. A $P$ value of less than 0.05 was considered to be significant.

\section{Acknowledgments}

We are grateful to Helio Takahashi, Yusuf Hannun, Lina Obeid, Deepak Bastia, Edward Balish, Lincoln Scott, and Carolina Westwater for discussion. Special thanks to Margaret Romano and to Russell Harley for invaluable help and discussion with the histology staining and to Stefka Spassieva for helping in the purification of GlcCer. We also thank all members of the M. Del Poeta and C. Luberto laboratories for guidance. We gratefully acknowledge John Oatis for helping with NMR analysis. This work was supported in part by the Burroughs Welcome Fund; NIH grant AI56168 (to M. Del Poeta); grants RR17677 Project 2 (to M. Del Poeta) and Project 6 (to C. Luberto) from the Centers of Biomedical Research Excellence Program of the National Center for Research Resources; National Science Foundation/EPSCoR grant \#EPS-0132573 (to C. Luberto); NIH grant C06 RR015455 from 
the Extramural Research Facilities Program of the National Center for Research Resources; and, for the sphingolipid analysis by mass spectrometry, NIH grant GM069338 (LIPID MAPS, to A.H. Merrill). M. Del Poeta is a Burroughs Wellcome New Investigator in Pathogenesis of Infectious Diseases.

Received for publication January 10, 2006, and accepted in revised form March 7, 2006.

1. Casadevall, A., and Perfect, J.R. 1998. Cryptococcus neoformans. ASM Press. Washington, DC, USA. 351-380.

2. Feldmesser, M., Tucker, S., and Casadevall, A. 2001. Intracellular parasitism of macrophages by Cryptococcus neoformans. Trends Microbiol. 9:273-278.

3. Levitz, S.M., et al. 1999. Cryptococcus neoformans resides in an acidic phagolysosome of human macrophages. Infect. Immun. 67:885-890.

4. Chretien, F., et al. 2002. Pathogenesis of cerebral Cryptococcus neoformans infection after fungemia. J. Infect. Dis. 186:522-530.

5. Feldmesser, M., Kress, Y., Novikoff, P., and Casadevall, A. 2000. Cryptococcus neoformans is a facultative intracellular pathogen in murine pulmonary infection. Infect. Immun. 68:4225-4237.

6. Lee, S.C., Kress, Y., Zhao, M.L., Dickson, D.W., and Casadevall, A. 1995. Cryptococcus neoformans survive and replicate in human microglia. Lab. Invest. 73:871-879.

7. Tucker, S.C., and Casadevall, A. 2002. Replication of Cryptococcus neoformans in macrophages is accompanied by phagosomal permeabilization and accumulation of vesicles containing polysaccharide in the cytoplasm. Proc. Natl. Acad. Sci. U. S. A. 99:3165-3170.

8. Steenbergen, J.N., Shuman, H.A., and Casadevall, A. 2001. Cryptococcus neoformans interactions with amoebae suggest an explanation for its virulence and intracellular pathogenic strategy in macrophages. Proc. Natl. Acad. Sci. U. S. A. 98:15245-15250.

9. Luberto, C., et al. 2001. Roles for inositol-phosphoryl ceramide synthase 1 (IPC1) in pathogenesis of C. neoformans. Genes Dev. 15:201-212.

10. Rodrigues, M.L., et al. 2000. Human antibodies against a purified glucosylceramide from Cryptococcus neoformans inhibit cell budding and fungal growth. Infect. Immun. 68:7049-7060.

11. Toledo, M.S., Suzuki, E., Levery, S.B., Straus, A.H., and Takahashi, H.K. 2001. Characterization of monoclonal antibody MEST-2 specific to glucosylceramide of fungi and plants. Glycobiology. 11:105-112.

12. Leipelt, M., et al. 2001. Glucosylceramide synthases, a gene family responsible for the biosynthesis of glucosphingolipids in animals, plants, and fungi. J. Biol. Chem. 276:33621-33629.

13. Matsubara, T., Hayashi, A., Banno, Y., Morita, T., and Nozawa, Y. 1987. Cerebroside of the dimorphic human pathogen, Candida albicans. Chem. Phys. Lipids. 43:1-12.

14. Leipelt, M., Warnecke, D.C., Hube, B., Zahringer, U., and Heinz, E. 2000. Characterization of UDPglucose:ceramide glucosyltransferases from different organisms. Biochem. Soc. Trans. 28:751-752.

15. Boas, M.H., Egge, H., Pohlentz, G., Hartmann, R., and Bergter, E.B. 1994. Structural determination of N-2'-hydroxyoctadecenoyl-1-O-beta-D-glucopyranosyl-9-methyl-4, 8-sphingadienine from species of Aspergillus. Chem. Phys. Lipids. 70:11-19.

16. Levery, S.B., et al. 2002. Disruption of the glucosylceramide biosynthetic pathway in Aspergillus nidu-
Address correspondence to: Maurizio Del Poeta, Department of Biochemistry and Molecular Biology, Medical University of South Carolina, 173 Ashley Avenue, BSB 503, Charleston, South Carolina 29425, USA. Phone: (843) 792-8381; Fax: (843) 792-8565; E-mail: delpoeta@musc.edu.

Philipp C. Rittershaus and Talar B. Kechichian contributed equally to this work. lans and Aspergillus fumigatus by inhibitors of UDPGlc:ceramide glucosyltransferase strongly affects spore germination, cell cycle, and hyphal growth. FEBS Lett. 525:59-64.

17. Toledo, M.S., Levery, S.B., Suzuki, E., Straus, A.H., and Takahashi, H.K. 2001. Characterization of cerebrosides from the thermally dimorphic mycopathogen Histoplasma capsulatum: expression of 2-hydroxy fatty $\mathrm{N}$-acyl (E)-Delta(3)-unsaturation correlates with the yeast-mycelium phase transition. Glycobiology. 11:113-124.

18. Takahashi, H.K., et al. 1996. Isolation and possible composition of glucosylceramides from Paracoccidioides brasiliensis. Braz. J. Med. Biol. Res. 29:1441-1444.

19. Toledo, M.S., Levery, S.B., Glushka, J., Straus, A.H., and Takahashi, H.K. 2001. Structure elucidation of sphingolipids from the mycopathogen Sporothrix schenckii: identification of novel glycosylinositol phosphorylceramides with core manalpha1-->6Ins linkage. Biochem. Biophys. Res. Commun. 280:19-24.

20. Warnecke, D., and Heinz, E. 2003. Recently discovered functions of glucosylceramides in plants and fungi. Cell. Mol. Life Sci. 60:919-941.

21. Hanada, K. 2005. Sphingolipids in infectious diseases. Jpn. J. Infect. Dis. 58:131-148.

22. Heung, L.J., Luberto, C., and Del Poeta, M. 2006. Role of sphingolipids in microbial pathogenesis. Infect. Immun. 74:28-39.

23. Pinto, M.R., et al. 2002. Characterization of glucosylceramides in Pseudallescheria boydii and their involvement in fungal differentiation. Glycobiology. 12:251-260.

24. Toledo, M.S., Suzuki, E., Straus, A.H., and Takahashi, H.K. 1995. Glycolipids from Paracoccidioides brasiliensis. Isolation of a galactofuranose-containing glycolipid reactive with sera of patients with paracoccidioidomycosis. J. Med. Vet. Mycol. 33:247-251.

25. Thevissen, K., et al. 2004. Defensins from insects and plants interact with fungal glucosylceramides. J. Biol. Chem. 279:3900-3905.

26. Nimrichter, L., et al. 2004. A monoclonal antibody to glucosylceramide inhibits the growth of Fonsecaea pedrosoi and enhances the antifungal action of mouse macrophages. Microbes Infect. 6:657-665.

27. Toledo, M.S., et al. 1999. Characterization of sphingolipids from mycopathogens: factors correlating with expression of 2-hydroxy fatty acyl (E)-Delta 3-unsaturation in cerebrosides of Paracoccidioides brasiliensis and Aspergillus fumigatus. Biochemistry. 38:7294-7306.

28. Toledo, M.S., Levery, S.B., Straus, A.H., and Takahashi, H.K. 2000. Dimorphic expression of cerebrosides in the mycopathogen Sporotbrix schenckii. J. Lipid Res. 41:797-806.

29. Villee, C.A. 1957. Biology. Saunders. Philadelphia, Pennsylvania, USA. 615 pp.

30. Levitz, S.M. 2001. Cryptococcus neoformans: intracellular or extracellular? Trends Microbiol. 9:417-418.

31. Saito, K., Takakuwa, N., Ohnishi, M., and Oda, Y. 2006. Presence of glucosylceramide in yeast and its relation to alkali tolerance of yeast. Appl. Microbiol. Biotechnol. 69:1-7.

32. Granger, D.L., Perfect, J.R., and Durack, D.T. 1985. Virulence of Cryptococcus neoformans. Regulation of capsule synthesis by carbon dioxide. J. Clin. Invest. 76:508-516.

33. Klengel, T., et al. 2005. Fungal adenylyl cyclase integrates $\mathrm{CO} 2$ sensing with cAMP signaling and virulence. Curr. Biol. 15:2021-2026.

34. Klotz, S.A., Drutz, D.J., Huppert, M., Sun, S.H., and DeMarsh, P.L. 1984. The critical role of CO2 in the morphogenesis of Coccidioides immitis in cell-free subcutaneous chambers. J. Infect. Dis. 150:127-134.

35. Mogensen, E.G., et al. 2006. Cryptococcus neoformans senses $\mathrm{CO} 2$ through the carbonic anhydrase Can2 and the adenylyl cyclase Cac1. Eukaryot. Cell. 5:103-111.

36. Bahn, Y.S., Cox, G.M., Perfect, J.R., and Heitman, J. 2005. Carbonic anhydrase and $\mathrm{CO} 2$ sensing during Cryptococcus neoformans growth, differentiation, and virulence. Curr. Biol. 15:2013-2020.

37. Ichikawa, S., Sakiyama, H., Suzuki, G., Hidari, K.I., and Hirabayashi, Y. 1996. Expression cloning of a cDNA for human ceramide glucosyltransferase that catalyzes the first glycosylation step of glycosphingolipid synthesis. Proc. Natl. Acad. Sci. U. S. A. 93:4638-4643.

38. Marks, D.L., Dominguez, M., Wu, K., and Pagano, R.E. 2001. Identification of active site residues in glucosylceramide synthase. A nucleotide-binding catalytic motif conserved with processive beta-glycosyltransferases. J. Biol. Chem. 276:26492-26498.

39. Bradford, M.M. 1976. A rapid and sensitive method for the quantitation of microgram quantities of protein utilizing the principle of protein-dye binding. Anal. Biochem. 72:248-254.

40. Sullards, M.C., Lynch, D.V., Merrill, A.H., Jr., and Adams, J. 2000. Structure determination of soybean and wheat glucosylceramides by tandem mass spectrometry. J. Mass. Spectrom. 35:347-353.

41. Mandala, S.M., et al. 1995. The discovery of australifungin, a novel inhibitor of sphinganine $\mathrm{N}$-acyltransferase from Sporormiella australis. Producing organism, fermentation, isolation, and biological activity. J. Antibiot. (Tokyo). 48:349-356.

42. Merrill, A.H., Jr., Sullards, M.C., Allegood, J.C., Kelly, S., and Wang, E. 2005. Sphingolipidomics: high-throughput, structure-specific, and quantitative analysis of sphingolipids by liquid chromatography tandem mass spectrometry. Methods. 36:207-224.

43. Delaglio, F., et al. 1995. NMRPipe: a multidimensional spectral processing system based on UNIX pipes. J. Biomol. NMR. 6:277-293.

44. Shaka, A.J., Lee, C.J., and Pines, A. 1988. Iterative schemes for bilinear operators; application to spin decoupling. J. Magn. Reson. 77:274-293.

45. Mersh, J.D., and Sanders, J.K.M. 1982. The suppression of Bloch-Siegert shifts and subtraction artifacts in double-resonance difference spectroscopy. J. Magn. Reson. 50:289-298. 